\title{
Estimation of allele-specific Ace-1 duplication in insecticide-resistant Anopheles mosquitoes from West Africa
}

Luc S. Djogbénou ${ }^{1,2^{*}}$, Benoît Assogba1', John Essandoh², Edi A. V. Constant ${ }^{2}$, Michel Makoutodé ${ }^{1}$, Martin Akogbéto ${ }^{3}$, Martin J. Donnelly² and David Weetman ${ }^{2}$

\begin{abstract}
Background: Identification of variation in Ace-1 copy number and G119S mutation genotype from samples of Anopheles gambiae and Anopheles coluzzii across West Africa are important diagnostics of carbamate and organophosphate resistance at population and individual levels. The most widespread and economical method, PCR-RFLP, suffers from an inability to discriminate true heterozygotes from heterozygotes with duplication.

Methods: In addition to PCR-RFLP, in this study three different molecular techniques were applied on the same mosquito specimens: TaqMan qPCR, qRTPCR and ddPCR. To group heterozygous individuals recorded from the PCR-RFLP analysis into different assumptive genotypes K-means clustering was applied on the Z-scores of data obtained from both the TaqMan and ddPCR methods. The qRTPCR analysis was used for absolute quantification of copy number variation.

Results: The results indicate that most heterozygotes are duplicated and that G119S mutation must now be regarded as a complex genotype ranging from primarily single-copy susceptible Glycine homozygotes to balanced and imbalanced heterozygotes, and multiply-amplified resistant Serine allele homozygotes. Whilst qRTPCR-based gene copy analysis suffers from some imprecision, it clearly illustrates differences in copy number among genotype groups identified by TaqMan or ddPCR. Based on TaqMan method properties, and by coupling TaqMan and ddPCR methods simultaneously on the same type of mosquito specimens, it demonstrated that the TaqMan genotype assays associated with the K-means clustering algorithm could provide a useful semi-quantitative estimate method to investigate the level of allele-specific duplication in mosquito populations.

Conclusions: Ace-1 gene duplication is evidently far more complex in An. gambiae and An. coluzzii than the betterstudied mosquito Culex quinquefasciatus, which consequently can no longer be considered an appropriate model for prediction of phenotypic consequences. These require urgent further evaluation in Anopheles. To maintain the sustained effectiveness carbamates and organophosphates as alternative products to pyrethroids for malaria vector control, monitoring of duplicated resistant alleles in natural populations is essential to guide the rational use of these insecticides.
\end{abstract}

\section{Background}

Copy number variations (CNVs) are defined as DNA sequences ranging from $1 \mathrm{~kb}$ to few $\mathrm{Mb}$ that have different numbers of repeats within or among individuals [1]

\footnotetext{
*Correspondence: Idjogbenou22002@yahoo.fr

${ }^{1}$ Institut Regional de Santé Publique de Ouidah/Université

d'Abomey-Calavi, Cotonou, Benin

Full list of author information is available at the end of the article
}

and arise from the duplication or deletion of DNA segments [2]. In the human genome, CNVs have been shown to be associated with several phenotypic effects [3-5]. Gene duplication is also thought to be the main potential source of material for the evolution of new gene functions [6] providing an important source of adaptive variation [7]. Several models have been proposed for the evolution of new functions through duplication, most 
based on ancient events [8], but duplication may also be important for adaptation to changing environmental conditions on a contemporary timescale.

Acetylcholinesterase (AChE) is the target of organophosphate and carbamate insecticides and catalyzes the hydrolysis of the neurotransmitter acetylcholine to terminate nerve impulses at the postsynaptic membrane. Mutations in the Ace-1 gene, which codes for $\mathrm{AChE}$ in insects such as the primary African malaria vector Anopheles gambiae species pair (Anopheles gambiae s.s. and Anopheles coluzzii), can confer resistance to carbamate and organophosphate compounds [9]. Of the mutations in the coding sequence of the Ace-1 gene recorded to date, only one, G119S (a single amino acid substitution, from a glycine to a serine at the position 119 in the AChE catalytic site using Torpedo californica nomenclature), is found in Anopheles, and causes strong resistance to both organophosphates and carbamates $[10,11]$. This substitution to the resistant allele $\left(\right.$ Ace- $\left.1^{R}\right)$ has a high fitness costs in insecticide-free environments [12, 13]. In Culex pipiens, Ace- $1^{R}$ has a very similar resistance: fitness cost profile [12]. However, duplicated alleles have evolved on several occasions in Culex which link a resistant allele $\left(A c e-1^{R}\right)$ with a susceptible allele $\left(A c e-1^{S}\right)$ on the same chromosome in permanent 'heterozygosity' [14] alleviating significant costs in field populations [15].

Subsequent discovery of an Ace-1 gene duplication event in An. gambiae [16] was thus a major concern for vector control. Furthermore, absence of sequence diversity in duplicated alleles argued for a single origin, despite detection in both An. gambiae s.s. and An. coluzzii from Burkina Faso and Côte d'Ivoire [16], and Ghana where it was found only on An. gambiae s.s. [11], suggesting that spread had already occurred.

An important goal is the development of methods capable of discovering Ace-1 gene copy number variations in field samples of mosquitoes in addition to genotyping G119S mutation alleles. Very recently, a qRT-PCR method to detect duplication was applied to individual female An. coluzzii from a multi-insecticide resistant population from Tiassalé, Côte d'Ivoire [17]. In Tiassalé most females are heterozygous at the Ace-1 locus $[10,18]$. Heterozygous individuals surviving bendiocarb exposure exhibited both a significantly higher resistant/susceptible allele ratio $\left(A c e-1^{R} / A c e-1^{S}\right)$ in the standard TaqMan genotyping assay and a higher Ace-1 gene copy number, assessed by the qRT-PCR, i.e. they survived because they possessed more copies of resistant alleles [10]. This first demonstration of a direct impact of Ace-1 gene copy number variation on insecticide resistance suggested that An. gambiae exhibits greater complexity of Ace-1 gene amplification (cf. 'duplication') than previously suspected, with potentially many gene copies and multiple resistant alleles. Moreover the results confirmed fears that Ace-1 copy number variation represents an emergent threat to vector control [19].

To investigate this effectively, and link Ace-1 gene copy number variation to insecticide resistance and fitness costs more widely in the field, widely-applicable detection methods for duplicated alleles are required. Understanding the distribution and spread of the frequency of the $A c e-1^{R}$ allele, particularly when coupled with duplication is of major concern for vector control programmes using carbamates and organophosphates for indoor residual spraying (IRS).

No simple test is available to detect and study Ace-1 duplication in mosquito species due to the lack of sequence features specific to copied alleles. Traditional PCR that visualizes PCR products run on a gel cannot readily discriminate duplicated alleles, which typically display as classical heterozygotes. Djogbenou et al. [19] attempted to estimate the duplicated allele $\left(\mathrm{Ag}-\mathrm{Ace}-\mathrm{I}^{\mathrm{D}}\right)$ frequency in a field population by using an indirect method previously developed for Cx. pipiens, but such statistical methods may conflate overdominance with duplication [20]. Approaches have been developed to screen for CNVs systematically at a whole-genome level in whole genome sequencing data $[21,22]$. However these methods cannot be applied easily to field populations, especially in resource-limited West African settings wherein the Ace-1 gene duplication is found in major malaria vector populations. Due to the lack of validated, field-applicable diagnostic tools, key questions arising from the previous research remain open:

How frequently does Ace-1 gene duplication occur in field populations?

What is the extent and consistency of duplication of susceptible and resistant alleles?

What is the contribution of duplicated alleles to insecticide resistance and other phenotypic traits in the field?

Providing responses to the above questions will help to better evaluate the potential consequences of the Ace-1 gene duplication event for An. gambiae resistant population management and on malaria control.

In this study, PCR-RFLP and TaqMan genotyping assays, qRT-PCR to detect copy number, and a newer digital droplet PCR method were applied to the same An. gambiae samples to explore variation in Ace-1 gene copy number across West Africa with the aim to identify appropriate strategies for identifying variation at population and individual levels in the main malaria vector. 


\section{Methods}

\section{Mosquito samples and DNA extraction}

The samples used in this study were field-collected adults originating from various locations across four West African countries (Table 1) and laboratory strains of known G119S genotype. Some of the field-collected samples were identified for inclusion by implementation of a duplicated haplotype detection protocol based on laboratory crossing and resistance phenotyping [14]. Genomic DNA was extracted from each field mosquito using DNeasy Tissue Kit according to the manufacturer's instructions.

\section{PCR-RFLP}

Ace-1 genotypes were first determined by using the available polymerase-chain reaction-restriction fragment length polymorphism (PCR-RFLP) analysis. The PCR primers and PCR protocol were designed according to a previously described method [16].

\section{TaqMan qPCR assay}

TaqMan is a semi-quantitative real-time polymerase chain reaction (PCR) method that uses fluorescent probes to measure amounts of target nucleic acid. The use of two allele-specific probes carrying different fluorophores allows SNP determination in the same tube with genotype usually determined from the ratio of their intensities at the end of amplification. DNA extracts of mosquitoes of known species were genotyped individually using a standard TaqMan assay laboratory protocol [23]; run on an Agilent Stratagene MX3000 qPCR thermal cycler, and scored from bi-directional scatter plots produced by the Agilent MxPro software after amplification.

Each $10 \mu \mathrm{L}$ PCR reaction contained $1 \mu \mathrm{L}$ of the genomic DNA of an individual mosquito, $5 \mu \mathrm{L}$ of SensiMixTM II Probe Kit (Bioline), $0.125 \mu \mathrm{L}$ of Primer/Probe kit at $\mathrm{A} \mu \mathrm{M}$ of each primer and $\mathrm{B} \mu \mathrm{M}$ of each probe (Applied Biosystems, Foster City, CA) and $3.875 \mu \mathrm{L}$ $\mathrm{ddH}_{2} \mathrm{O}$. The PCR cycling conditions were as follows: an initial denaturation at $95{ }^{\circ} \mathrm{C}$ for $10 \mathrm{~min}$, followed by 40 cycles of $95{ }^{\circ} \mathrm{C}$ for $10 \mathrm{~s}$ and $60^{\circ} \mathrm{C}$ for $45 \mathrm{~s}$. The increase in HEX and FAM fluorescence was monitored in real time by detecting fluorescence on the yellow (530 nm excitation and $555 \mathrm{~nm}$ emission) and green channels (470 nm excitation and 510 emission) of the qPCR thermal cycler, respectively. All samples were analysed simultaneously in the same qPCR run.

\section{Digital droplet PCR}

Digital droplet PCR (ddPCR) combines partitioning of a qPCR reaction into many thousands of individual droplets in a water-oil emulsion, with the use of flow cytometry to count positive PCR amplicons [24]. In this work, digital droplet PCR reactions were performed using the same TaqMan primers and probes as above [23]. Reaction mixes were prepared as follows: $10 \mathrm{~mL}$ of $2 \times$ ddPCR Master Mix (BioRad) and $0.125 \mu \mathrm{L}$ of Primer/ Probe kit (Applied Biosystems, Foster City, CA), $2 \mu \mathrm{L}$ of DNA template and $3.5 \mu \mathrm{L}$ of nuclease-and proteasefree water (Sigma-Aldrich Chemie Gmbh, Munich, Germany) and were added to complete a $20 \mu \mathrm{L}$ reaction volume and mixed. The $20 \mu \mathrm{L}$ mixture of each sample and reagents were divided into $\sim 20,000$ droplets for PCR amplification of single template molecules. Thermal cycling conditions for the assays consisted of an activation period $\left(5 \mathrm{~min}\right.$ at $95^{\circ} \mathrm{C}$ ) followed by 40 cycles of a two-step thermal profile comprising of a 40 cycles of a two-step thermal profile comprising of a denaturation step $\left(30 \mathrm{~s}\right.$ at $\left.94{ }^{\circ} \mathrm{C}\right)$ and a combined annealing extension. The ddPCR workflow followed an established protocol [24] and data analysis was performed as described below and in Supplementary file S1 (Additional file 1). All samples were analysed simultaneously in a single ddPCR experiment.

\section{Quantitative real-time PCR}

Primers and the protocol for a copy-number qPCR method have been described previously [17], but briefly involve amplification of three fragments of the Ace-1 gene, with two endogenous reference genes used for sample normalisation, elongation factor 1-alpha (EF-1) and the P450 gene Cyp4g16. In An. gambiae Cyp4g16 is located on the $\mathrm{X}$ chromosome allowing preliminary assessment of quantitative efficacy of amplification by comparison of males and females.

For all assays two known control samples (carrying one copy of the gene) termed calibrators (CA1 and CA2) and a no-template control (NTC) were included. The copy number of Ace-1 was estimated relative to two pools of gDNA from females of two strains susceptible to organophosphates and carbamates (Kisumu and Okyereko). The reaction mixture contained $1 \times$ Power SYBR Green Master Mix (Applied Biosystems, Foster City, CA, USA), 1 pmol of each primer, $1 \mu \mathrm{L}$ of template DNA and distilled ultra-pure water for a final reaction volume of $10 \mu \mathrm{L}$. The reactions were set up in a 96-well optical reaction plate (Applied Biosystems, Foster City, CA, USA) and run on an Agilent Stratagene real-time thermal cycler and analysed using Agilent's MXPro software $(\mathrm{Mx} 3005 \mathrm{P})$. The PCR conditions used throughout were $10 \mathrm{~min}$ for $95^{\circ} \mathrm{C}, 40$ cycles of $10 \mathrm{~s}$ at $95^{\circ} \mathrm{C}$ and $60{ }^{\circ} \mathrm{C}$ respectively, with melting curves run after each end point amplification at $1 \mathrm{~min}$ for $95^{\circ} \mathrm{C}$, followed by $30 \mathrm{~s}$ increments of $1{ }^{\circ} \mathrm{C}$ from 55 to $95^{\circ} \mathrm{C}$. 
Table 1 Names and genotypes (from PCR-RFLP) of samples and their sources

\begin{tabular}{|c|c|c|c|}
\hline Countries & Specimens & PCR-RFLP genotyping & Sources \\
\hline \multirow[t]{14}{*}{ Burkina Faso } & Boromo G3 & Ace. $1^{5 S}$ & Larval collection \\
\hline & Boromo 25 & Ace. $1^{R S}$ & Larval collection \\
\hline & Dano D6 & Ace. $1^{R S}$ & Larval collection \\
\hline & Boromo B2 & Ace. $1^{R S}$ & Larval collection \\
\hline & Dano C7 & Ace. $1^{R S}$ & Larval collection \\
\hline & Dano 34 & Ace. $1^{R S}$ & Larval collection \\
\hline & Dano 33 & Ace. $1^{R S}$ & Larval collection \\
\hline & Vallée du Kou A10 & Ace. $1^{R S}$ & Larval collection \\
\hline & Orodara D11 & Ace. $1^{R S}$ & Larval collection \\
\hline & Orodara 6.4 & Ace. $1^{R S}$ & Larval collection and crossing protocol \\
\hline & Orodara 8.10 & Ace. $1^{R S}$ & Larval collection and crossing protocol \\
\hline & Orodara 8.22 & Ace. $1^{R S}$ & Larval collection and crossing protocol \\
\hline & Orodara A9 & Ace. $1^{R R}$ & Larval collection \\
\hline & Orodara 8.13 & Ace. $1^{R S}$ & Larval collection and crossing protocol \\
\hline \multirow[t]{10}{*}{ Côte d'Ivoire } & Sikensis 12 & Ace. $1^{\text {SS }}$ & Larval collection \\
\hline & Daloua 11 & Ace. $1^{\text {SS }}$ & Larval collection \\
\hline & Sikensis 1 & Ace. $1^{\text {SS }}$ & Larval collection \\
\hline & Divo 5 & Ace. $1^{R S}$ & Larval collection \\
\hline & Divo 1 & Ace. $1^{R S}$ & Larval collection \\
\hline & Divo 7 & Ace. $1^{R S}$ & Larval collection \\
\hline & Tiassalé 21 & Ace. $1^{R S}$ & Larval collection \\
\hline & Divo 3 & Ace. $1^{R S}$ & Larval collection \\
\hline & Toumodi 2 & Ace. $1^{R S}$ & Larval collection and crossing protocol \\
\hline & Toumodi 8 & Ace. $1^{R S}$ & Larval collection and crossing protocol \\
\hline \multirow[t]{8}{*}{ Ghana } & Okyereko & Ace. $1^{S S}$ & Larval collection \\
\hline & Cape-Coast 5 & Ace. $1^{R S}$ & Larval collection \\
\hline & Koforidua 7 & Ace. $1^{R S}$ & Larval collection \\
\hline & Ashaman 9 & Ace. $1^{R R}$ & Larval collection \\
\hline & Ashaman 5 & Ace. $1^{R R}$ & Larval collection \\
\hline & Koforidua 18 & Ace. $1^{R R}$ & Larval collection \\
\hline & Ashaman 4 & Ace. $1^{R R}$ & Larval collection \\
\hline & Koforidua 3 & Ace. $1^{R R}$ & Larval collection \\
\hline \multirow[t]{6}{*}{ Laboratory strain } & Kisumu 1 & Ace. $1^{\text {SS }}$ & Laboratory colony \\
\hline & Kisumu 8 & Ace. $1^{\text {SS }}$ & Laboratory colony \\
\hline & Kisumu 3 & Ace. $1^{\text {SS }}$ & Laboratory colony \\
\hline & DD1 & Ace. $1^{R S}$ & Crossing protocol \\
\hline & DD2 & Ace. $1^{R S}$ & Crossing protocol \\
\hline & Acerkis & Ace. $1^{R R}$ & Laboratory colony \\
\hline \multirow[t]{3}{*}{ Togo } & Baguida 77 & Ace. $1^{R S}$ & Larval collection and crossing protocol \\
\hline & Baguida 99 & Ace. $1^{R S}$ & Larval collection and crossing protocol \\
\hline & Baguida 6.5 & Ace. $1^{R R}$ & Larval collection and crossing protocol \\
\hline
\end{tabular}

\section{Data analysis}

TaqMan assay: raw data comprised of the final fluorescence values (dRLast), defined as the amount of fluorescence from each reporter dye at the completion of cycling, were imported into Microsoft Excel software and the ratio of dRLast FAM/dRLast HEX (' $R_{\text {TaqMan }}$ ') was computed and used for further statistical analysis. ddPCR assay: following scanning on a QX100 droplet reader (Bio-Rad Laboratories Inc.), data were analyzed with QuantaSoft software (Bio-Rad Laboratories Inc) following published algorithms [25]. The threshold was set manually at the lowest point of the negative 
droplet cluster, as visualized on each of the FAM and HEX probes. The ddPCR results were expressed as the number of droplets where amplification has or has not occurred (positive and negatives, respectively). In the case of this study, where a FAM/HEX duplex assay was performed, four discrete clusters of droplets are possible: (1) no target allele (negative FAM/negative HEX), indicative of a negative control or failed assay; $(2,3)$ only one of the targets is positive (negative FAM/positive HEX, or positive FAM/negative HEX), indicative of a homozygote; or (4) both targets are positive (positive FAM/positive HEX), indicative of a heterozygote. Results from (2), (3) and (4) can be used to compute the average number of copies of PCR amplicons for each allele $\left(\lambda_{\text {Ace-1 }}^{R}\right.$ and $\lambda_{\text {Ace-1 }}^{S}$, respectively for resistant and susceptible alleles at the Ace-1 locus) based on the fraction of positive droplets and Poisson modeling using the following formula $\{a\}$ : $-\ln (1-(\mathrm{p} / \mathrm{T}))$ where $\mathrm{p}$ is the number of positive droplets containing each amplified allele, and $\mathrm{T}$ is the number of positives droplets. From the data the number of copies from the ratio of $\lambda$ estimates for each allele was determine.

For the ddPCR assay the ratio data was first transformed to produce a distribution close to normal (see Additional file 1), using the logarithm of $R_{d d P C R}$, given by the equation $\{b\}: X=\ln \left(R_{d d P C R}\right)$. To test the difference in the logarithm of the observed ratio between Ace- $1^{R}$ and the reference $\left(A c e-1^{S}\right)$ from zero, the standard deviation of $\mathrm{X}$ (estimated from the equation $\{b\}$ above) was calculated. The variance of the $\log$ ratio $\mathrm{X}$ was determined using the equation $\{\mathrm{c}\}$ : $\sigma^{2} \mathrm{X}=(1-\operatorname{EXP}(\lambda 119 \mathrm{~S})) /\left(\mathrm{T} \times \lambda^{2} 119 \mathrm{~S} \times \operatorname{EXP}(\lambda 119 \mathrm{~S})\right)+$ $(1-\operatorname{EXP}(\lambda 119 G)) /\left(C \times \lambda^{2} 119 S \times \operatorname{EXP}(\lambda 119 G)\right)$. With the variance in the log ratio, the upper and lower $95 \% \mathrm{CI}$ were calculated (see Additional file 1) for others formulas used in this section. Finally, the X values and their standard deviations for each test sample were plotted.

Copy-number qRT-PCR: data analysis followed the delta-delta $\mathrm{Ct}(\Delta \Delta \mathrm{Ct})$ method of relative quantification [26] to estimate copy numbers of the Ace-1 gene (averaged across the three primer pairs) as described in Edi et al. [17]. To group heterozygous individuals recorded from the PCR-RFLP analysis (Table 1) into different assumptive genotypes K-means clustering (using squared Eucliden distances and an iterative method) was applied on the Z-scores of the correspondent data obtained from both TaqMan and ddPCR methods. The variances in their scores explained by the clustering solution were calculated using analysis of variance (ANOVA). The statistical software package ade4 in R-project version 3.1.2 [27] was used to perform these analysis.

\section{Results}

Using PCR-RFLP assays, a total of 41 female An. gambiae and An. coluzzii mosquitoes collected from 14 locations across four countries were analysed. These comprised of six specimens of known PCR-RFLP Ace-1 genotype (three homozygous Ace- $1^{S S}$; two heterozygous $A c e-1^{R S}$ and one homozygous Ace- $\left.1^{R R}\right)$; and 35 individuals of unknown Ace-1 genotype. Of these 35 fieldcollected specimens 23 (65.7\%) typed as heterozygous, seven (20\%) were homozygous Ace- $1^{R R}$ and five (14.3\%) were homozygous Ace-1 ${ }^{S S}$ (Table 1).

The same 41 DNA samples were genotyped using the TaqMan assay, plotting baseline-corrected endpoint values (dRLast) for each dye (FAM and HEX) in a bidirectional scatter-plot (Fig. 1). Classically, high HEX fluorescence alone indicates a homozygote for the wild allele of acetylcholinesterase enzyme termed Ace-1 ${ }^{S S}$ (homozygote susceptible), high FAM fluorescence alone indicates a homozygote resistant $\left(A c e-1^{R R}\right)$ and high signals in each dye indicate a heterozygote termed Ace- $1^{R S}$. The diffuse and fragmented nature of apparent heterozygotes (Fig. 1) means that simple genotypic designation cannot be easily made using the standard method of calling [23].

After droplet digital PCR reactions, the average number of accepted droplet reactions in each ddPCR was $12365 \pm 1876$. By considering the Ace- $1^{S}$ allele as the reference the R-value that is the ratio of $\lambda$ (number of copies of PCR amplicons for each allele) estimates for each allele $\left(\mathrm{R}_{\mathrm{ddPCR}}=\lambda_{A c e-1}^{R} / \lambda_{A c e-1}^{S}\right)$ was determined (see Additional file 1).

K-means cluster analysis using separately TaqMan $\left(\mathrm{R}_{\text {TaqMan }}\right)$ and ddPCR $\left(\mathrm{R}_{\mathrm{ddPCR}}\right)$ data was used to group individuals typing as heterozygotes in the PCR-RFLP assay (Fig. 1). Samples were clustered into three genotype groups (named gcII, gcIII and gcIV) as shown in Fig. 2. Based on these clusters, manual annotation to the TaqMan scatter plot highlighted five clusters: the three recorded above and homozygous susceptible individuals termed $g_{c I}$ (genotype cluster I) and homozygous resistant individuals termed $g c V$ (genotype cluster V) (Fig. 3). Results from the ddPCR assay are shown in Fig. 4 with samples arranged left to right in order of increasing ratio of resistance allele signal $\left(\lambda_{\text {Ace- } 1}^{R} / \lambda_{\text {Ace-1 }}^{S}\right)$ values; the five groups of specimen genotypes are indicated.

Ace-1 gene copy number varied dramatically among the samples assayed. Assuming that the calibrators used in this study have only two copies of the Ace-1 gene as expected for a diploid with a single copy gene, some samples carry an estimated five copies of the Ace-1 locus. Results indicate both a high rate of CNVs at this locus and a broad geographical spread (Fig. 5). There was a 


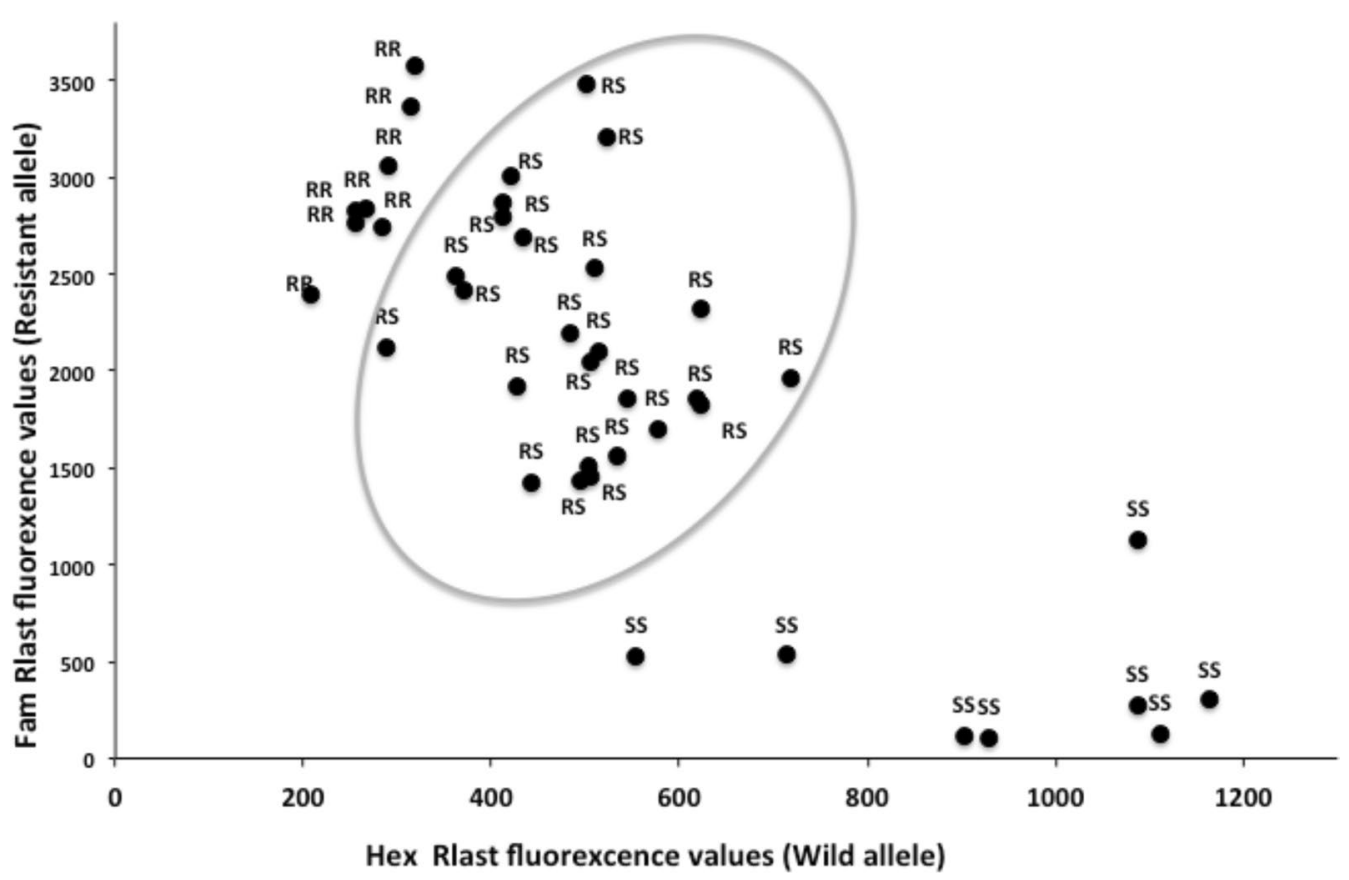

Fig. 1 Scatter plot analysis of TaqMan fluorescence data. dRlast fluorescence values of the FAM labelled probe (specific for the Ace- $7^{R}$ mutation) are plotted against the HEX labelled probe (specific for the wild type $A c e-1^{S}$ allele). RR, genotype Ace- $1^{R R}$; RS, genotype Ace- $1^{R S}$; SS, genotype Ace- $1^{S S}$. The circle indicates the limit of heterozygous specimens

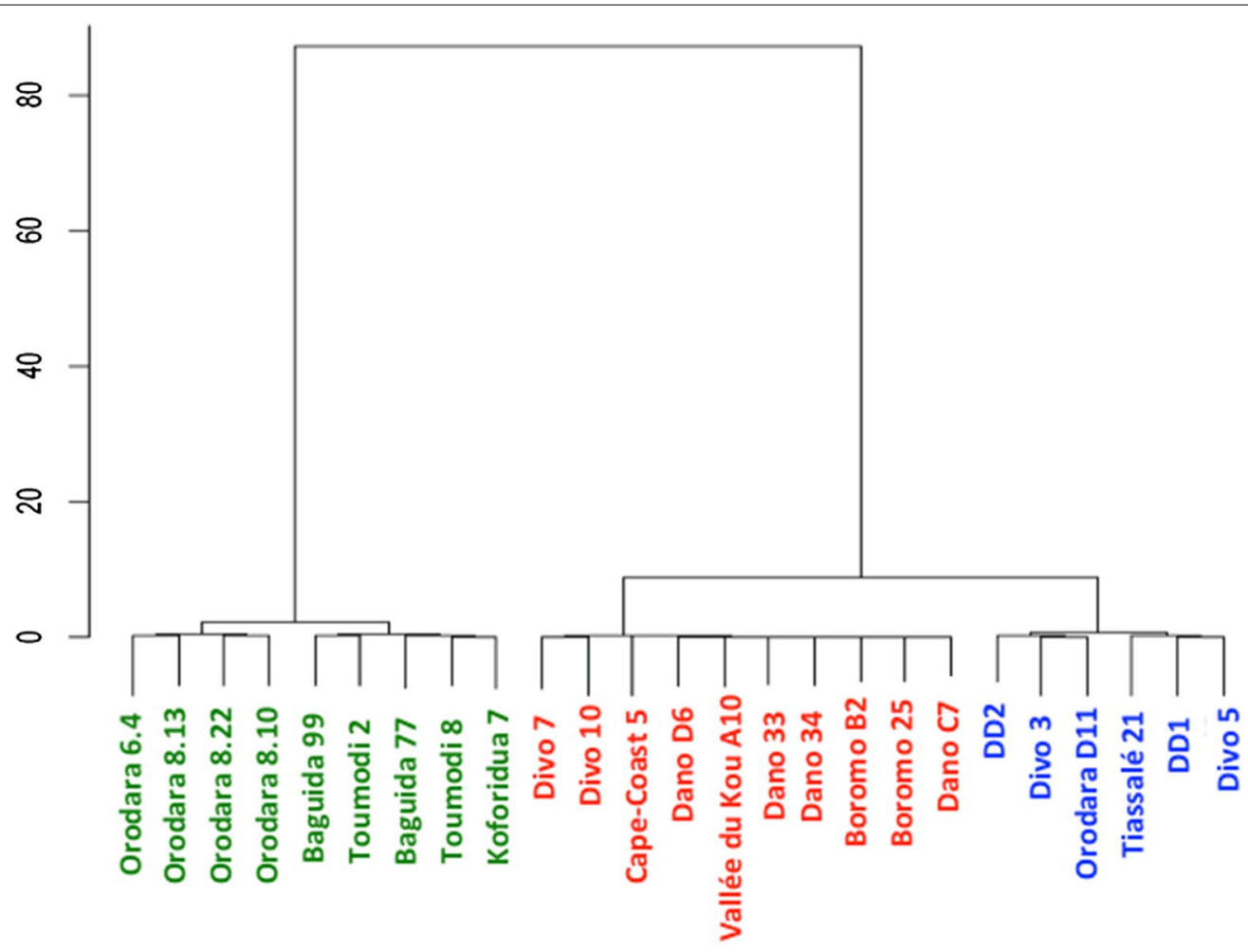

Genotype $g c l l$

Genotype gcIII

Genotype gcIV

Fig. 2 Dendrogram from k-means clustering analysis showing genotype calling groups obtained from specimens bearing both Ace-1 alleles 


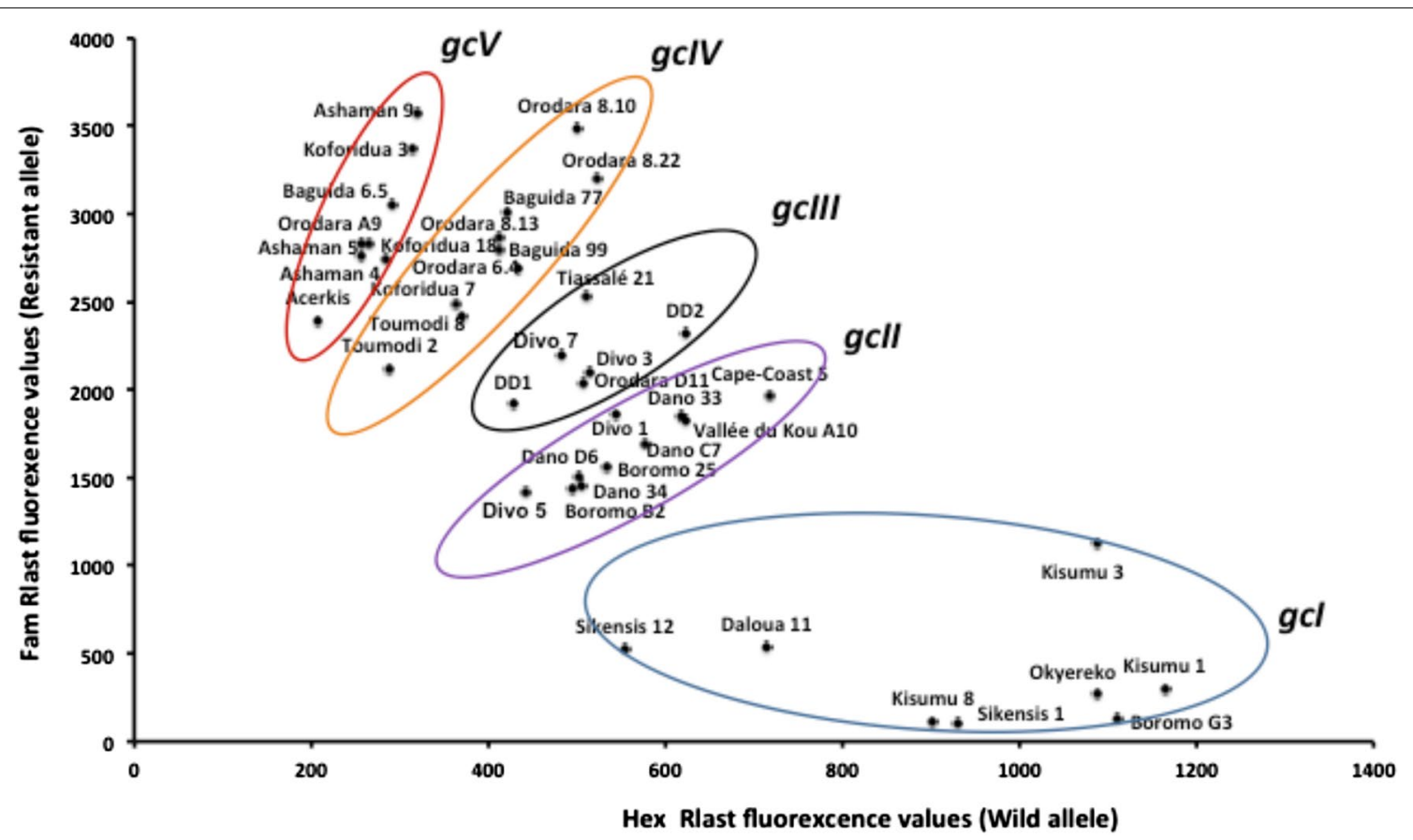

Fig. 3 Scatter plot analysis of TaqMan fluorescence data showing different genotype clusters, denoted by different coloured circles

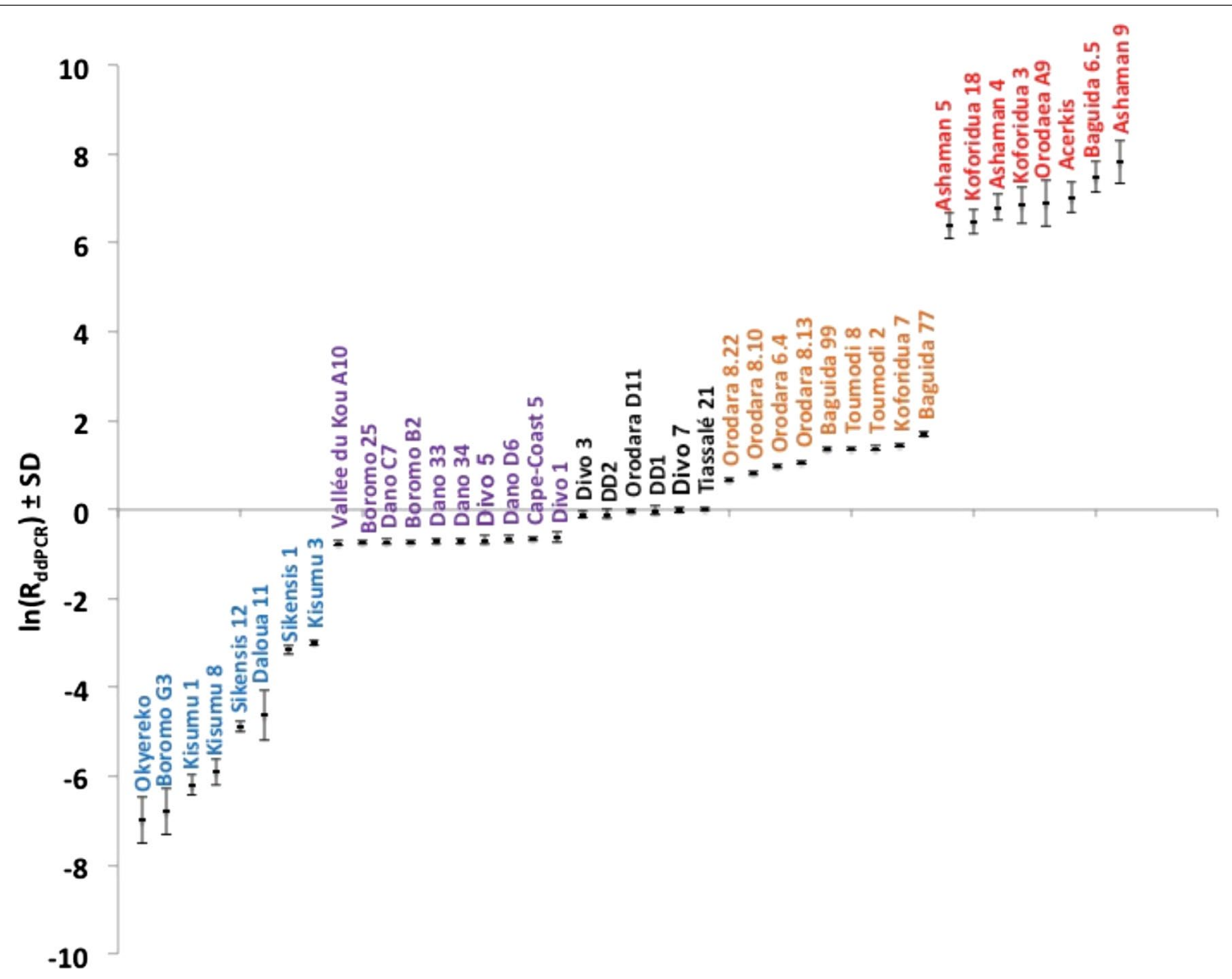

Fig. 4 Plot of the $\log \left(R=\lambda_{1195} / \lambda_{119 G}\right)$ computed from the raw data obtained from ddPCR assays 


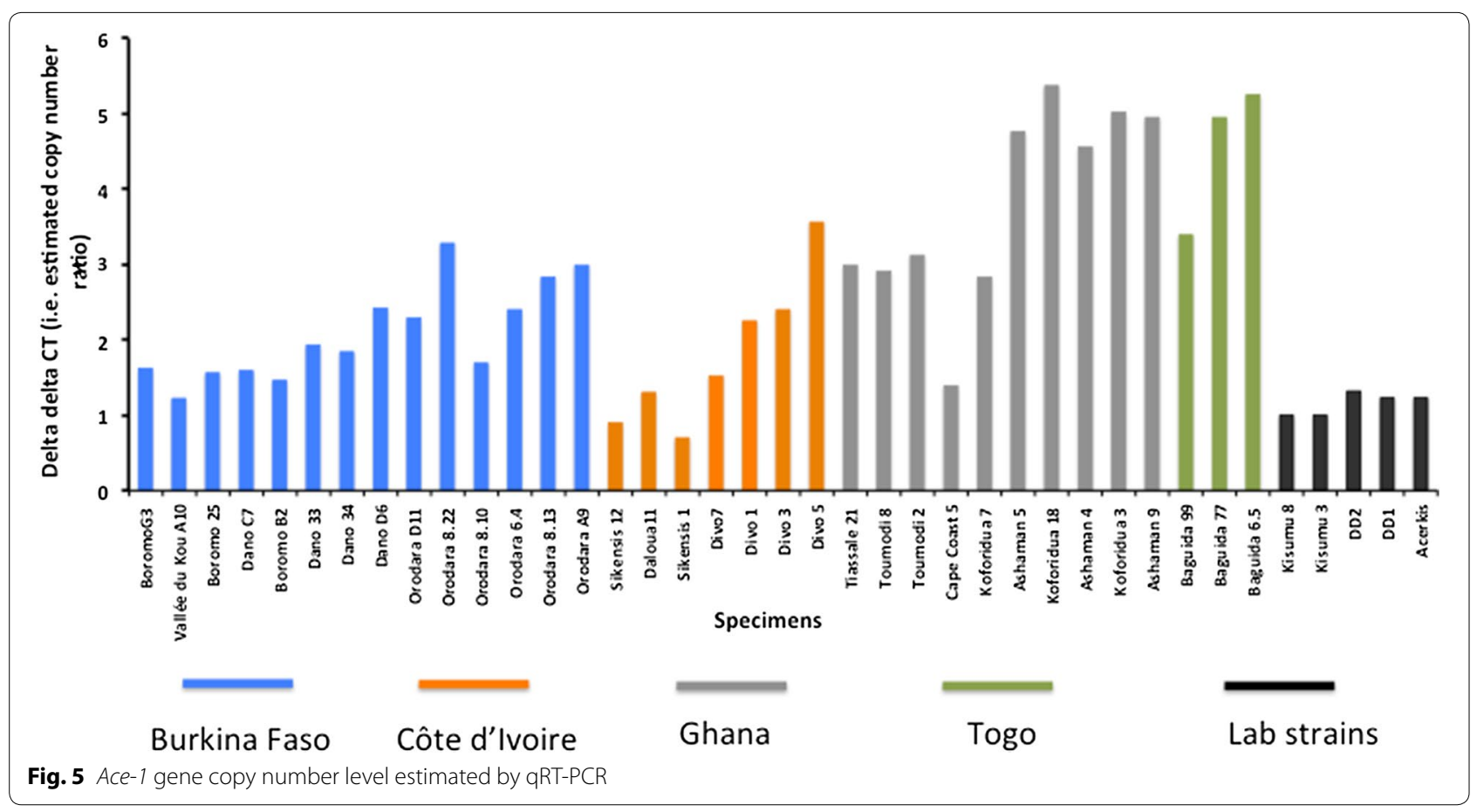

strong and highly significant difference in copy number (estimated from the qRTPCR) among the groups identified by TaqMan and ddPCR (ANOVA: $\mathrm{F}_{4,38}=18.4$, $\mathrm{P}=4 \times 10^{-8}$ ) with a progressive increase from a singlecopy average for susceptible homozygotes (Gn), suggesting that all or most are unduplicated, to resistant homozygotes $(\mathrm{Sn})$ which averaged in excess of four gene copies (Fig. 6). This suggests that resistant alleles are far more likely to be duplicated than susceptible and, importantly, that groupings from TaqMan (or ddPCR) give a meaningful semi-quantitative indication of copy number variation detected by the quantitative, but not allele-specific, qRTPCR method.

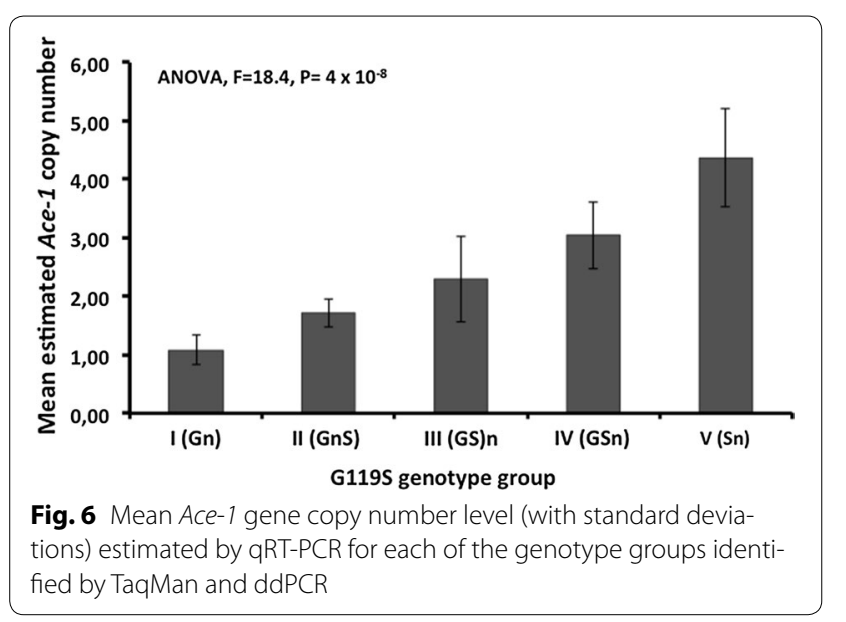

\section{Discussion}

Occurrence of duplication of Ace-1 has been detected in both Culex quinquefasciatus and An. gambiae [14, 28] but the lack of a specific test (enzymatic or molecular) to detect duplications has been an impediment to understanding their nature and impacts. Identification of individuals harboring duplicated alleles by designing crosses and observing progeny survival in bioassays [14] is too time-consuming to allow proper interpretation of $\mathrm{CNV}$ in $A c e-1^{R S}$ genotypes scored using the traditional PCRRFLP technique [29]. Indeed these represent a highly heterogeneous group, which in An. coluzzii from Tiassale (which almost all type as heterozygotes in PCR-RFLP), exhibit significantly variable bioassay survival [17]. With Ace-1 CNV apparently now spread across such a broad area of West Africa, assays giving insight into CNV variation of the kind which were evaluate here, are urgently required.

In addition to PCR-RFLP, three different molecular techniques were applied on the same mosquito specimens (either collected from field or provided from laboratory strains). TaqMan genotyping is a high throughput and highly accurate methodology widely used for detection of target site mutations in mosquitoes [30, 31]. ddPCR has been adopted for a number of applications, including studies of copy number variation involving allelic discrimination or imbalance, single cell gene expression, detection of low copy number nucleic acid targets $[32,33]$ and of point mutations. Though giving 
Table 2 Different clusters observed, with suggested genotype calls obtained from both TaqMan and ddPCR data followed by K-means clustering analysis

\begin{tabular}{|c|c|c|c|}
\hline $\mathbf{N}^{\circ}$ & $\begin{array}{l}\text { Genotype } \\
\text { cluster }(g c)\end{array}$ & Samples & $\begin{array}{l}\text { Estimates } \\
\text { genotypes }\end{array}$ \\
\hline 1 & \multirow[t]{8}{*}{ I } & Okyereko & \multirow{8}{*}{$\begin{array}{l}\text { Gn: Homozygous susceptible } \\
\text { individuals }\left(A c e-1^{n S 5} \text { ) with Ace- }\right. \\
1 \text { gene copy number greater } \\
\text { than or equal to } 1\end{array}$} \\
\hline 2 & & Boromo G3 & \\
\hline 3 & & Kisumu 1 & \\
\hline 4 & & Kisumu 8 & \\
\hline 5 & & Sikensis 12 & \\
\hline 6 & & Daloua 11 & \\
\hline 7 & & Sikensis 1 & \\
\hline 8 & & Kisumu 3 & \\
\hline 9 & \multirow[t]{10}{*}{$\|$} & Vallée du Kou & \multirow{10}{*}{$\begin{array}{l}\text { GnS: Heterozygous individuals } \\
\left(\text { Ace- } 1^{\text {GnS }}\right) \text { with more suscep- } \\
\text { tible copies than resistant } \\
\text { copies }\end{array}$} \\
\hline 10 & & Boromo 25 & \\
\hline 11 & & Dano C7 & \\
\hline 12 & & Boromo B2 & \\
\hline 13 & & Dano 33 & \\
\hline 14 & & Dano 34 & \\
\hline 15 & & Divo 5 & \\
\hline 16 & & Dano D6 & \\
\hline 17 & & Cape-Coast 5 & \\
\hline 18 & & Divo 1 & \\
\hline 19 & \multirow[t]{6}{*}{ III } & Divo 3 & \multirow{6}{*}{$\begin{array}{l}\text { (GS)n: Heterozygous individu- } \\
\text { als }(\text { Ace-1(GS)n) with equal of } \\
\text { susceptible and resistant allele } \\
\text { and Ace-1 gene copy number } \\
\text { greater than or equal to } 1\end{array}$} \\
\hline 20 & & DD2 & \\
\hline 21 & & Orodara D11 & \\
\hline 22 & & DD1 & \\
\hline 23 & & Divo 7 & \\
\hline 24 & & Tiassalé 21 & \\
\hline 25 & \multirow[t]{9}{*}{ IV } & Orodara 8.22 & \multirow{9}{*}{$\begin{array}{l}\text { GSn: Heterozygous individuals } \\
\left(\text { Ace- }{ }^{G S n}\right) \text { with more resistant } \\
\text { allele than susceptible one }\end{array}$} \\
\hline 26 & & Orodara 8.10 & \\
\hline 27 & & Orodara 6.4 & \\
\hline 28 & & Orodara 8.13 & \\
\hline 29 & & Baguida 99 & \\
\hline 30 & & Toumodi 8 & \\
\hline 31 & & Toumodi 2 & \\
\hline 32 & & Koforidua 7 & \\
\hline 33 & & Baguida 77 & \\
\hline 34 & \multirow[t]{8}{*}{ V } & Ashaman 5 & \multirow{8}{*}{$\begin{array}{l}\text { Sn: homozygous resistant } \\
\text { individuals }\left(\text { Ace- } 1^{\text {Sn }} \text { ) with Ace-1 }\right. \\
\text { gene copy number greater } \\
\text { than or equal to } 1\end{array}$} \\
\hline 35 & & Koforidua 18 & \\
\hline 36 & & Ashaman 4 & \\
\hline 37 & & Koforidua 3 & \\
\hline 38 & & Orodaea A9 & \\
\hline 39 & & Acerkis & \\
\hline 40 & & Baguida 6.5 & \\
\hline 41 & & Ashaman 9 & \\
\hline
\end{tabular}

high precision estimation of allelic balance for heterozygotes, ddPCR cannot give quantitative insight into CNV level in homozygotes or $\mathrm{GnSn}$ heterozygotes with an equal allele balance. With the TaqMan method, instead of having clearly distinct expected cluster patterns [23] it was displayed a large spectral distribution of heterozygous individuals that rendered manual genotype calling of subgroups difficult. Therefore attempts have been made to automatically assign genotype using K-means on the transformed fluorescence data generated by both TaqMan and ddPCR techniques. A clear separation of heterozygous genotype subgroups was obtained, to supplement the straightforward identification of the distinct homozygous groups, and these clusters exhibited significant variation in mean CNV level assessed by the copy number detection qRTPCR (Fig. 4). This cross-comparability between techniques suggests that where separation of heterozygote sub-groups is the primary aim, TaqMan and ddPCR assays can provide useful semi-quantitative estimation of copy number variation. Most, if not all, of the susceptible homozygote individuals in this study appear to possess only a single copy of Ace-1, consistent with results from Accra, Ghana [34], therefore application of the qRTPCR assay to samples genotyping as glycine homozygotes may be a lesser priority. However to investigate the resistance consequences of variation in resistant allele copy number in resistant (serine) homozygotes, genotyping will need to be supplemented by SYBR green qPCR.

By interpreting each genotype cluster position in the Fig. 3 following genotype calls are suggest (see Table 2):

- Gn: genotype cluster I = homozygous susceptible individuals $\left(\right.$ Ace- $\left.1^{n S S}\right)$.

- GnS: genotype cluster II = heterozygous individuals $\left(\right.$ Ace-1 $\left.{ }^{\text {GnS }}\right)$.

- (GS)n: genotype cluster III = heterozygous individuals $\left(\right.$ Ace-1 $\left.1^{(G S) n}\right)$.

- GSn: genotype cluster IV = heterozygous individuals $\left(\right.$ Ace- $\left.1^{G S n}\right)$.

- Sn: genotype cluster $\mathrm{V}=$ homozygous resistant individuals $\left(\right.$ Ace- $\left.1^{\text {Sn }}\right)$.

Previous studies discovered, what appeared to be rare, duplications of Ace-1 in An. gambiae (and An. coluzzii) $[11,28]$ via the occurrence of a resistant and two distinct susceptible alleles in sequence data from single individuals. In contrast, results of the present study indicated that duplication event is very prevalent and spans a range of possible genotypes involving multiple resistant alleles. Furthermore, the highest copy number was recorded in individuals with a strong imbalance of resistant to susceptible copies in contrast with previous findings in Culex [14]. Anopheles gambiae thus seems to exhibit far greater complexity of duplication at the Ace-1 gene. 


\section{Additional file}

Additional file 1: Statistical analysis of row data obtained from ddPCR method. The data provided represent the average number of copies of PCR amplicons and the number of copies from the ratio of $\lambda$ estimates for each allele in each sample.

\section{Authors' contributions}

Conceived and designed and performed the experiments, analyzed data: LSD, DW, MJD. Contributed reagents/materials/analysis tools: AB, JE, EAVC, MM, AM. Wrote the paper: LSD, DW, MJD. All authors read and approved the final manuscript.

\section{Author details \\ ${ }^{1}$ Institut Regional de Santé Publique de Ouidah/Université d'Abomey-Calavi, Cotonou, Benin. ${ }^{2}$ Department of Vector Biology, Liverpool School of Tropical Medicine, Pembroke Place, Liverpool, UK. ${ }^{3}$ Centre de Recherche Ento- mologique de Cotonou, Cotonou, Benin.}

\section{Acknowledgements}

We are grateful to Emily Rippon, Keith Steen Stephen Hague (Droplet Digital PCR Specialist) for their technical support. We would also like to thank the following people; Seth Irish, Audrey Lenhart and Brogdon William G. for providing useful comments on earlier versions of the manuscript. This work was supported by Wellcome Trust Master's Training Fellowship in Public Health and Tropical Medicine Grant WT093755.

\section{Competing interests}

The authors declare that they have no competing interests.

Received: 3 September 2015 Accepted: 2 December 2015 Published online: 18 December 2015

\section{References}

1. Feuk L, Carson AR, Scherer SW. Structural variation in the human genome. Nat Rev Genet. 2006;7:85-97.

2. Freeman JL, Perry GH, Feuk L, Redon R, McCarroll SA, Altshuler DM, et al. Copy number variation: new insights in genome diversity. Genome Res. 2006;16:949-61.

3. Cooper GM, Nickerson DA, Eichler EE. Mutational and selective effects on copy-number variants in the human genome. Nat Genet. 2007;39:S22-9.

4. Stankiewicz P, Lupski JR. Structural variation in the human genome and its role in disease. Annu Rev Med. 2010;61:437-55.

5. Zhang F, Gu W, Hurles ME, Lupski JR. Copy number variation in human health, disease, and evolution. Annu Rev Genom Hum Genet. 2009;10:451-81.

6. Ohta T. Role of gene duplication in evolution. Genome. 1989;31:304-10.

7. LiWH. Evolution of duplicated genes. In: Koehin RK, NEI M, editors. Evolution of genes and proteins. Sunderland: Sinauer; 1983. p. 14-37.

8. Innan H, Kondrashov F. The evolution of gene duplications: classifying and distinguishing between models. Nat Rev Genet. 2010;11:97-108.

9. Oakeshott JG, Devonshire AL, Claudianos C, Sutherland TD, Horne I, Campbell PM, et al. Comparing the organophosphorus and carbamate insecticide resistance mutations in cholin- and carboxyl-esterases. Chem Biol Interact. 2005;157-158:269-75.

10. Edi CV, Koudou BG, Jones CM, Weetman D, Ranson H. Multiple-insecticide resistance in Anopheles gambiae mosquitoes, Southern Cote d'Ivoire. Emerg Infect Dis. 2012;18:1508-11.

11. Essandoh J, Yawson AE, Weetman D. Acetylcholinesterase (Ace-1) target site mutation 1195 is strongly diagnostic of carbamate and organophosphate resistance in Anopheles gambiae s.s. and Anopheles coluzzii across southern Ghana. Malar J. 2013;12:404.

12. Alout H, Djogbenou L, Berticat C, Chandre F, Weill M. Comparison of Anopheles gambiae and Culex pipiens acetycholinesterase 1 biochemical properties. Comp Biochem Physiol B: Biochem Mol Biol. 2008;150:271-7.
13. Djogbenou L, Noel V, Agnew P. Costs of insensitive acetylcholinesterase insecticide resistance for the malaria vector Anopheles gambiae homozygous for the G119S mutation. Malar J. 2010;9:12.

14. Labbe P, Berthomieu A, Berticat C, Alout H, Raymond M, Lenormand T, et al. Independent duplications of the acetylcholinesterase gene conferring insecticide resistance in the mosquito Culex pipiens. Mol Biol Evol. 2007;24:1056-67.

15. Labbe P, Berticat C, Berthomieu A, Unal S, Bernard C, Weill M, et al. Forty years of erratic insecticide resistance evolution in the mosquito Culex pipiens. PLoS Genet. 2007;3:e205

16. Djogbenou L, Dabire R, Diabate A, Kengne P, Akogbeto M, Hougard JM, et al. Identification and geographic distribution of the ACE-1R mutation in the malaria vector Anopheles gambiae in South-Western Burkina Faso, West Africa. Am J Trop Med Hyg. 2008;78:298-302.

17. Edi CV, Djogbenou L, Jenkins AM, Regna K, Muskavitch MA, Poupardin $R$, et al. CYP6 P450 enzymes and ACE-1 duplication produce extreme and multiple insecticide resistance in the malaria mosquito Anopheles gambiae. PLoS Genet. 2014;10:e1004236.

18. Ahoua Alou LP, Koffi AA, Adja MA, Tia E, Kouassi PK, Kone M. Distribution of ace-1R and resistance to carbamates and organophosphates in Anopheles gambiae s.s. populations from Cote d'Ivoire. Malar J. 2010;9:167.

19. Djogbenou L, Labbe P, Chandre F, Pasteur N, Weill M. Ace-1 duplication in Anopheles gambiae: a challenge for malaria control. Malar J. 2009;8:70.

20. Lenormand T, Guillemaud T, Bourguet D, Raymond M. Appearance and sweep of a gene duplication: adaptative response and potential for new functions in the mosquito Culex pipiens. Evolution. 1998;52:1705-12.

21. Bickhart DM, Hou Y, Schroeder SG, Alkan C, Cardone MF, Matukumalli LK, et al. Copy number variation of individual cattle genomes using nextgeneration sequencing. Genome Res. 2012;22:778-90.

22. Zhao Q, Han MJ, Sun W, Zhang Z. Copy number variations among silkworms. BMC Genom. 2014;15:251.

23. Bass C, Nikou D, Vontas J, Williamson MS, Field LM. Development of high-throughput real-time PCR assays for the identification of insensitive acetylcholinesterase (ace-1R) in Anopheles gambiae. Pestic Biochem Phys. 2010;96:80-5.

24. Pinheiro LB, Coleman VA, Hindson CM, Herrmann J, Hindson BJ, Bhat S, et al. Evaluation of a droplet digital polymerase chain reaction format for DNA copy number quantification. Anal Chem. 2012;84:1003-11.

25. Whale AS, Huggett JF, Cowen S, Speirs V, Shaw J, Ellison S, et al. Comparison of microfluidic digital PCR and conventional quantitative PCR for measuring copy number variation. Nucleic Acids Res. 2012;40:e82.

26. Livak KJ, Schmittgen TD. Analysis of relative gene expression data using real-time quantitative PCR and the 2(-Delta Delta $C(T))$ method. Methods. 2001;25:402-8.

27. Chessel D, Dufour AB, Thioulouse J. The ade 4 package-l: one-table methods. News. 2004:4:5-10.

28. Djogbenou L, Chandre F, Berthomieu A, Dabire R, Koffi A, Alout H, et al. Evidence of introgression of the ace-1(R) mutation and of the Ace-1 duplication in West African Anopheles gambiae s. s. PLoS One. 2008;3:e2172.

29. Weill M, Malcolm C, Chandre F, Mogensen K, Berthomieu A, Marquine M, et al. The unique mutation in ace-1 giving high insecticide resistance is easily detectable in mosquito vectors. Insect Mol Biol. 2004;13:1-7.

30. Chen L, Zhong D, Zhang D, Shi L, Zhou G, Gong M, et al. Molecular ecology of pyrethroid knockdown resistance in Culex pipiens pallens mosquitoes. PLoS One. 2010;5:e11681.

31. Yanola J, Somboon P, Walton C, Nachaiwieng W, Somwang P, Prapanthadara LA. High-throughput assays for detection of the F1534C mutation in the voltage-gated sodium channel gene in permethrin-resistant Aedes aegypti and the distribution of this mutation throughout Thailand. Trop Med Int Health. 2011;16:501-9.

32. Hindson BJ, Ness KD, Masquelier DA, Belgrader P, Heredia NJ, Makarewicz AJ, et al. High-throughput droplet digital PCR system for absolute quantitation of DNA copy number. Anal Chem. 2011;83:8604-10.

33. Miotke L, Lau BT, Rumma RT, Ji HP. High sensitivity detection and quantitation of DNA copy number and single nucleotide variants with single color droplet digital PCR. Anal Chem. 2014;86:2618-24.

34. Weetman D, Mitchell SN, Wilding CS, Birks DP, Yawson AE, Essandoh J, et al. Contemporary evolution of resistance at the major insecticide target site gene Ace-1 by mutation and copy number variation in the malaria mosquito Anopheles gambiae. Mol Ecol. 2015;24:2656-72. 